\title{
UM ESTUDO HISTÓRICO-INSTITUCIONAL DO PROGRAMA TERRA LEGAL DE REGULARIZAÇÃO FUNDIÁRIA NA AMAZÔNIA
}

\section{A HISTORICAL-INSTITUTIONAL STUDY OF THE TERRA LEGAL OF LAND REGULARIZATION PROGRAM IN THE AMAZON}

GABRIEL MORAES OUTEIRO ${ }^{1}$

\begin{abstract}
RESUMO: O aumento da informalidade em assentamentos urbanos tem tornado a regularização fundiária uma questão fundamental nas cidades brasileiras. $\mathrm{Na}$ Amazônia, devido ao seu processo histórico de ocupação, que produziu desigualdade social, este é um assunto ainda mais relevante, o que levou à formulação do Programa Terra Legal de regularização fundiária urbana, com vistas à garantia do direito fundamental à moradia, garantido constitucionalmente. Este estudo tem por escopo analisar o Programa Terra Legal, sob o arcabouço teórico do neoinstitucionalismo. Trata-se de pesquisa qualitativa, que se utilizou de pesquisa bibliográfica e documental. Como principal resultado, constatou-se que o Programa Terra Legal se caracteriza mais como um ajuste incremental dentro da mesma trajetória de exclusão socioespacial, com efeitos limitados rumo à democratização do acesso ao solo.
\end{abstract}

Palavras-Chave: Neoinstitucionalismo; Regularização Fundiária Urbana; Programa Terra Legal; Amazônia Legal..

ABSTRACT: Increasing informality in urban settlements has made land regularization a key issue in Brazilian cities. In the Amazon, due to its historical occupation process, which produced social inequality, this is an even more relevant issue, which led to the formulation of the Terra Legal Program of urban land

1 Doutor em Desenvolvimento Socioambiental pelo NAEA/UFPA. Doutorando em Direito pelo PPGD/UFPA. Mestre em Direito pelo PPGD/UFPA. Especialista em Direito Tributário pela Universidade Anhanguera-Uniderp. Diretor-Geral do Instituto de Ciências Sociais Aplicadas da Universidade Federal do Sul e Sudeste do Pará - ICSA/Unifesspa. Professor da Unifesspa. Advogado. Contato: gmouteiro@gmail.com. 
regularization. This study analyzes the Terra Legal Program, guided on neoinstitutionalism's theoretical framework. It is a qualitative research, which used bibliographic and documentary research. As a main result, it was verified that the Terra Legal Program is more characterized as an incremental adjustment within the same trajectory same trajectory of socio-spatial exclusion, with limited effects towards the democratization of access to land.

KEYWORDS: Neo-institutionalism; Urban Land Regularization; Terra Legal Program; Legal Amazon.

\section{INTRODUÇÃO}

No Brasil o número de habitações irregulares tem se multiplicado durante as últimas décadas em todas as regiões do país, com um déficit de domicílios adequados de cerca de 6 milhões (BRASIL, 2015), dentre os quais parte está em situação de inadequação fundiária urbana.

É possível relacionar o quadro atual com a origem da estrutura fundiária nacional no Direito Português, que utilizou o sistema sesmarial lusitano para definir o acesso à terra, que privava qualquer indivíduo desprovido de posses suficientes de receber a concessão de terra, gerando exclusão social no acesso a este bem (TRECCANI, 2009) e, consequentemente, forçando estas pessoas a viverem em algum local de forma irregular. Este problema é agravado na Amazônia pelo seu histórico de ocupação e de sobreposição de títulos que vai do período colonial até o republicano (LOUREIRO, 2009).

Em contraposição a esta realidade, adotando-se a promoção da qualidade de vida como elemento propulsor da elaboração de políticas urbanas, é possível afirmar que a Constituição Federal (CF) de 1988 prevê um rol de direitos fundamentais, destinados a garantir a todos uma vida digna.

Deste conjunto de direitos fundamentais reconhecidos no texto constitucional, um grupo em especial chama a atenção, por possuir certas peculiaridades. Os direitos sociais têm como finalidade assegurar a igualdade material entre os indivíduos, servindo como mecanismo de promoção de igualdade e de bem-estar (COURTIS; ABRAMOVICH, 2006).

Por isso, adotou-se como foco da discussão sobre igualdade e qualidade de vida nas cidades, o direito social à moradia, incluído no art. $6^{\circ}$, da Carta de 88 , por meio da Emenda à Constituição no 26 de 2000. Este direito é um dos núcleos do direito à cidade, por estar relacionado a outros direitos, como infraestrutura urbana e serviços 
públicos, fazendo com que o tópico tenha ganhado destaque na seara jurídica, com diversos diplomas internacionais e documentos normativos nacionais tratando do objeto.

Diante dessa problemática, a regularização fundiária urbana (Reurb) é uma alternativa de política pública para o tratamento de áreas já ocupadas irregularmente (AZEVEDO, 2016), garantindo a segurança jurídica da posse e o direito social à moradia.

A segurança jurídica da posse e a atuação dos entes federados num programa de Reurb são temas que podem ser analisados sob o prisma institucional. As instituições, que podem ser leis, regras formais ou informais, são as principais variáveis para explicar as diferenças de qualidade de vida e de crescimento econômico entre regiões e países, ao reduzir as incertezas das quais depende uma sociedade (HALL; TAYLOR, 1996).

A visão institucional da questão fundiária contribui na análise dos fatores de bloqueio da mudança, que reproduzem no presente escolhas políticas feitas no passado, ainda que ineficientes. Por isso, é imprescindível um movimento de mudança institucional em favor de melhores mecanismos de demarcação e definição de direitos de propriedade.

A questão que se pretende responder é: em que medida o desenho institucional do Programa Terra Legal (PTL) explica o avanço ou fracasso do processo de regularização fundiária em municípios amazônicos?

O objetivo geral da pesquisa é analisar o desempenho do programa de regularização fundiária Terra Legal, a partir da dinâmica político-institucional, que produziu um quadro de caracterizado pela presença de expressivo grau regulatório da União e uma gama de atribuições nos municípios.

Trata-se de pesquisa com abordagem qualitativa, que se utilizou de pesquisa bibliográfica e documental. Como fonte secundária, foram estudados documentos oficiais e institucionais disponíveis na rede mundial de computadores.

A pesquisa foi estruturada em capítulos, a partir da seção introdutória. No capítulo seguinte está exposto o referencial teórico, que permite um olhar mais integrado do PTL na Amazônia, apresentando conceitos e definições doutrinárias, expondo a sua conexão com o federalismo brasileiro, como uma arena de repartição territorial de poder, que reflete opções específicas para a coordenação de políticas urbanas.

O terceiro capítulo, de natureza histórica, expõe de forma breve elementos importantes para a compreensão da situação atual da Amazônia, no que tange à irregularidade fundiária. Para em seguida, construir critérios de análise sob o olhar 
neoinstitucionalista, que propiciam estudar o PTL no capítulo quarto e, então, tecer as considerações finais.

\section{O INSTITUCIONALISMO HISTÓRICO COMO ABORDAGEM PARA O ESTUDO DE POLÍTICAS PÚBLICAS DE REGULARIZAÇÃO FUNDIÁRIA}

O estudo das instituições e do papel dos atores tem ganhado espaço no campo do exame das políticas públicas. A importância do debater as configurações políticas é evidenciada quando se nota que muitos assuntos, como mobilidade urbana, planejamento urbano e sustentabilidade, têm entrado na pauta de discussão da sociedade e cada decisão sobre o tema acaba afetando a coletividade. Quando a questão envolve políticas habitacionais não é diferente, já que existe todo um arcabouço legislativo e nem sempre se consegue a sua implementação satisfatoriamente.

A possibilidade de discutir a igualdade e como o Estado a concretizará também decorre do custo a ser arcado pelos cidadãos dos programas públicos, que em muitos casos são formulados para concretizar direitos. Segundo Holmes e Sunstein (1999), todo e qualquer direito garantido demandará a realização de gastos se exigir algum aparato do Estado, independente da sua qualificação ou nomenclatura.

Assim, inicialmente, antes de tratar mais especificamente do institucionalismo histórico como referencial teórico de análise políticas públicas, é imprescindível tecer breves considerações sobre o novo institucionalismo, em especial, pelo diálogo que há entre Direito e as instituições.

Todavia, deve-se advertir que não há unanimidade quanto a esta classificação, nem há uma escola destas vertentes na qual se encontrem postulados comuns. $\mathrm{Na}$ perspectiva neoinstitucionalista, as instituições norteiam a ação humana, que em diferentes momentos decide em favor de uma determinada política em detrimento de outra. Ocorre que, de acordo com Hall e Taylor (1996), é possível identificar várias vertentes teóricas que floresceram influenciadas por transformações nas instituições sociais, políticas e econômicas, dentre as quais está o institucionalismo histórico.

De acordo com Steinmo (2008), a diferença chave entre o institucionalismo histórico e os demais está na compreensão da natureza do ator que se comporta conforme o desenho institucional existente. Atores podem ser indivíduos, pequenos corpos coletivos, organizações ou grupos maiores.

As instituições moldam o comportamento individual e reduzem incertezas, funcionando como mediações entre as estruturas sociais e o comportamento individual: eles buscam maximizar seus interesses e seguem regras e padrões cognitivos construídos pela tradição (STEINMO, 2008). 
Assim, mesmo que os agentes façam um cálculo para maximizar seus interesses, suas preferências são constituídas socialmente, a tornar as decisões fruto de uma combinação destas duas lógicas, em que cada uma pode ter um peso maior, conforme o caso. Nesta vertente, instituições são regras formais e informais, que configuram estrutura política. Constituição Federal e o arcabouço jurídico que disciplina o rol de direitos fundamentais, por exemplo, são instituições

Do ponto de vista da maximização de rendimentos, o comportamento é estratégico e os indivíduos tendem a aderir a modelos de padrões, nos quais perderão mais ao evitá-los do que ao aderir a eles - há um sistema de benefícios e penalidades.

A origem das instituições nesta vertente está relacionada com a dinâmica de estruturação das relações de poder em uma comunidade política (STEINMO, 2008).

\section{INSTITUCIONALISMO HISTÓRICO E ANÁLISE DE POLÍTICAS PÚBLICAS}

O institucionalismo histórico não é uma teoria em particular ou um método específico, antes, é mais bem entendido como uma alternativa para examinar políticas públicas (STEINMO, 2008). As instituições alinham as ações e expectativas dos atores numa sociedade (FRIEL, 2017).

Desse modo, foca-se no desenvolvimento de políticas públicas, tendo em vista os momentos singulares de decisão, que irão afetar futuras decisões e a dinâmica entre os atores políticos. $\mathrm{Na}$ arena do jogo político, eles lutam por recursos escassos, com fulcro na estrutura institucional existente.

Os institucionalistas históricos se ocupam do exame de configurações organizacionais, momentos de transformação estrutural e processos de longo prazo, a tornar visível e inteligível o contexto e os processos de interação que definem (e redefinem) o Estado, o jogo político e o resultado de políticas públicas (SKOCPOL; PIERSON, 2002).

As instituições, enquanto um conjunto de regras de determinada arena decisória, irão influenciar os atores que atuam naquele jogo - ainda que para pessoas de fora desta arena seja difícil medir a influência ou o nível de constrangimento que tais instituições irão exercer sobre os jogadores, em especial se foram regras informais. As preferências individuais vão levar em consideração sanções e incentivos como consequências de seu comportamento, ou seja, um comportamento racional a partir das instituições que existem e do sentido atribuído a situação.

A herança institucional tem sido utilizada nos estudos do institucionalismo histórico, no sentido de que após o início de um caminho, os custos para reverter o 
rumo são altos, pois a despeito da existência de novos pontos de escolha, os arranjos institucionais tendem a autorreforçar a escolha inicial.

Portanto, a história importa. Estes dois temas, persistência das instituições passadas e mudança institucional, entraram na pauta do neoinstitucionalismo. Após o início de um caminho, as instituições proveem obstáculos para certas escolhas que alterem o rumo, e diminuem as opções futuras.

Ocorre que, mesmo que as instituições importem, não são elas que definem o produto final, tendo por fio condutor que são criadas e modificadas pelo ser humano. Então, apesar da relevância dada às instituições, estas não são consideradas as únicas forças causais no jogo político. Outros aspectos, como ideias, crenças e desenvolvimento socioeconômico, podem alterar os resultados, tratando-se de um mundo mais complexo do que aquele em que existe apenas preferências individuais e instituições.

Nessa linha de raciocínio, há uma miríade de variáveis, interrelacionadas, que devem ser levadas em conta no exame do processo histórico - há contexto, atores, regras formais e informais, processo de aprendizado, singularidade do momento, que podem afetar o produto do jogo político.

Os estudiosos deste eixo teórico não se resumem às observações sobre o passado, pois o que é mais pertinente é a percepção de processos ao longo do tempo (SKOCPOL; PIERSON, 2002).

\section{Path dependence}

A mão pesada da história, que constrange o futuro de variadas formas, traz uma inquietação: como as instituições participam, ao mesmo de tempo, das condições que impulsionam a mudança e cerceiam as opções dos agentes bloqueando novas modificações (IMMERGUT, 2006).

Além de modificações incrementais, transformações mais expressivas são possíveis em situações de alterações estruturais. Mas ao constranger as alternativas de escolha, as instituições projetam ao longo do tempo seus efeitos. A trajetória dependente é um conceito para compreender os motivos pelos quais algumas inovações, nem sempre as mais eficientes, dominavam mercados em detrimentos de outras (NORTH, 1990). Mas Fernandes (2002) explica que a tradição de estudar a política observando a trajetória histórica é antiga nas ciências sociais.

Nessa perspectiva, opções políticas passadas funcionam como um legado, a afetar o presente, como um fluxo de eventos históricos, em que há períodos de estabilidade e em algumas ocasiões acontecem mudanças institucionais substantivas. Estas conjunturas oferecem trânsito a novos caminhos, inacessíveis anteriormente. 
Os institucionalistas históricos incorporam a noção de que eventos aleatórios podem desencadear uma trajetória inicial, mas consideram que a história não é uma cadeia de eventos independentes (STEINMO, 2008), o que traz uma leitura peculiar dos processos de retornos crescentes, ao atribuir aos atores e jogos de poder certa relevância (CAPOCCIA; KELEMEN, 2007). Primeiramente, uma instituição se relaciona com um conjunto mais amplo de instituições, o que faz com a mudança em uma tenha implicações em outras, que podem oferecer resistência às modificações por meio de atores que tenham mais influência (na prática, é possível instituir um programa como o PTL, sem alterar as regras de registro de imóveis, que está em outra lei).

Em segundo lugar, indivíduos formam expectativas sobre as instituições existentes e podem ter receio de que mudanças tenham efeitos imprevisíveis (como o caso de titulares de cartórios que podem se unir para impedir modificações que garantam gratuidade para a Reurb de interesse social).

Finalmente, com o tempo, as instituições podem moldar as preferências individuais e fazer com que as pessoas optem por manter as normas com as quais estão acostumados, pois investiram tempo e recursos no seu aprendizado (STEINMO, 2008).

Logo, Capoccia e Kelemen (2007) ensinam que os principais responsáveis pela manutenção das instituições são atores com influência, o que faz com que quando se inicia uma trajetória, atores relevantes passam a ajustar suas estratégias para se acomodar ao novo padrão vigente e dificultam mudanças que possam lhes prejudicar.

Nesses termos, até a continuidade numa trajetória depende de constante atuação de atores políticos com influência e poder de barganha. Em suma, para Thelen (2006) estas considerações demonstram que há particularidades na aplicação de path dependence na política, pois aqui o foco reside em pontos de escolha.

$\mathrm{Na}$ análise da política, path dependence é uma forma de centralizar o estudo na ordem de eventos e no momento de certos acontecimentos (IMMERGUT, 2006), pois o jogo político é um processo que muitas vezes produz efeitos indesejados e nem sempre é coerente (THELEN, 2006).

Em suma, a ênfase é dada aos processos históricos, em que as instituições são produtos concretos da passagem do tempo, que emergem dentro de um contexto político e social. Isto faz com que as instituições não sejam compreendidas se forem isoladas do seu contexto político e com que a trajetória dependente abrace a continuidade, mas também seja aberta a mudanças estruturais (THELEN, 2006).

Para CAPOCCIA (2016) é possível ver o jogo político como arenas de conflito, nas quais atores que elaboram as normas formais (como políticos e coalisões partidárias), 
vão competir em conjunto com atores que devem cumprir as regras (como cidadãos, igrejas, escolas, sindicatos), para que a instituição (norma a ser aprovada) seja adaptada conforme seus interesses e agendas - tratando-se de uma mudança endógena em que pode haver evolução, retrocesso ou até extinção de uma instituição.

Outra forma de compreender o jogo político e a atuação dos atores é a partir das lições de Tsebelis (1998), apesar de seu pensamento integrar a escola dos rational choicers, que mostra como a previsibilidade do comportamento dos envolvidos no processo político pode se beneficiar da Teoria dos Jogos.

De modo geral, num jogo político o participante, caso tenha informações adequadas, irá escolher a opção que lhe assegure a maximização de seus interesses, sendo a racionalidade uma correspondência ótima entre fins e meios e a ação individual uma adaptação ótima a um ambiente institucional (TSEBELIS, 1998).

Mas então porque ao se observar o comportamento de certo ator, ele parece não ser o melhor (ótimo)? Nesse caso o observador não considerou que existem jogos ocultos, e por isso considera certas escolhas como sendo irracionais. Para Tsebelis, muitas vezes o observador atenta apenas para o jogo que ocorre na arena principal, não percebendo que existem jogos em múltiplas arenas (TSEBELIS, 1998). Apenas o estudo das múltiplas arenas e rede de jogos revela as motivações e explica o comportamento dos jogadores, mesmo que a decisão não vise ao bem comum.

Logo, a mudança institucional poderá depender do comportamento destes atores. Acontece que alguns desenhos institucionais atribuem a determinados jogadores, individuais ou coletivos, o poder de opinar diante de decisões políticas - seja para concordar ou vetar (veto players) a mudança no status quo.

Para Levi (1991) as instituições criam poder, no sentido de que regras formais podem conferir maior poder para certos grupos (como políticos) de manter ou alterar as instituições vigentes, o que pode ser um empecilho para efetivar uma mudança institucional. Assim, sugere que uma forma de grupos com menor poder de barganha ou de influência podem ter para forçar uma mudança institucional é se opondo às instituições e não as aceitando, em especial quando notarem que outros atores estão abusando de sua posição em certo arranjo institucional.

Estas observações reforçam que afirmar que as instituições importam não é o mesmo que dizer que apenas as instituições explicam todos os fenômenos políticos, ou que em alguns casos pode ser importante complementar este approach com outro referencial teórico (THELEN, 1999). Diante de todo o exposto, é possível avançar para compreender um pouco da história de ocupação da Amazônia. 


\section{UMA BREVE HISTÓRIA DO DIREITO DE PROPRIEDADE NO BRASIL E DOS SEUS IMPACTOS NA AMAZÔNIA}

Para entender a Reurb e compreender o PTL na Amazônia é necessária a assimilação de alguns eventos históricos acerca da formação desse espaço e de sua estrutura fundiária. A importância que programas estatais de regularização fundiária têm assumido está ligada a este passado: a irregularidade fundiária tem sido a regra, pelo menos para parte da população em todo o Brasil (SÁ, 2017), ainda que na Amazônia esta situação seja agravada devido ao seu processo de ocupação (LOUREIRO, 2009; OLIVEIRA; FISCHER, 2016).

A disputa por terras ao longo da história do Brasil gerou marcas na sua estrutura fundiária, em face da sucessão de instrumentos para garantir a posse e propriedade, advindos da legislação colonial, imperial, federal e estadual, mas que nem sempre se constituíram em direito adquirido dos ocupantes, a ser respeitado posteriormente (TRECCANI, 2009). Esta trajetória pode ser dividida em 4 períodos: regime de sesmarias (1500-1821), regime das posses (1821 a 1850), regime da lei de terras (1850 1889) e período republicano (1889 até os dias atuais) (TRECCANI, 2009).

Segundo Tavares (2011), após a chegada dos portugueses, inicia-se a ocupação militar na Amazônia no séc. XVI, com a fundação de Belém-PA, em 1616, para defender a soberania portuguesa no território brasileiro das invasões holandesas, francesas e inglesas.

Aa partir da incorporação do território brasileiro ao domínio lusitano, as áreas nacionais se tornaram originalmente públicas e somente o rei português poderia permitir o acesso à terra (PRIETO, 2016). No mesmo sentido, a consolidação da coroa portuguesa fez com que a estrutura fundiária nacional herdasse institutos do direito português, como o regime das sesmarias, a incentivar a formação de um Estado personalista, preocupado em atender os interesses dos governantes, sem separar a esfera pública da vida privada (FAORO, 2001).

O sistema de sesmaria determinava que a transferência de domínio da terra somente seria realizada após o cumprimento de algumas obrigações, que incluíam a sua efetiva utilização. Este sistema deu início à formação de latifúndios, por ter sido implantado com base em critérios pessoais e econômicos, excluindo pessoas de menor poder aquisitivo, problema que persiste até hoje (PRIETO, 2016).

Sem legislação fundiária e já independente de Portugal, o Brasil entrou no período das posses, que perdurou até 1850. Nesse momento, coexistiram áreas ocupadas com sesmarias confirmadas pelo regime anterior; possuidores legítimos, mas sem confirmação e possuidores de áreas sem autorização estatal ou sem regulamentação (ou que descumpriram com alguma de suas obrigações), e terras 
devolutas. Nesses últimos casos, a posse acabou gerando uma situação de fato sem proteção jurídica, piorando o caos fundiário (AZEVEDO, 2016).

Em 1824 é outorgada a primeira Constituição do Brasil, sob a influência do pensamento que concebia a propriedade como um direito absoluto (Prieto, 2016), mas sem disciplinar a sua forma de aquisição. Até que, no reinado de Dom Pedro II, é sancionada a Lei de Terras (Lei no 601/1850), criando instrumentos para a regularização fundiária, a exemplo do instituto da legitimação das posses, que era o ato por meio do qual o Estado reconhecia ao particular a sua condição de legitimidade, conferindo o formal domínio pleno, desde que este trabalhe na terra, como se observava no art. $5^{\circ}$, caput, Lei de Terras.

Apesar dos avanços que a Lei de Terras representa para a história, os efeitos socioespaciais de sua aplicação geraram malefícios, como concentração fundiária em favor de poucos indivíduos com recursos financeiros e exclusão social de pessoas de baixa renda (PRIETO, 2016).

Em primeiro lugar, a partir da Lei de Terras quem podia ter direito a terras era quem possuía recursos econômicos. Como consequência, excluiu o camponês, o imigrante estrangeiro sem influência política ou econômica e ex-escravos do direito à terra.

Segundo Prieto (2016), a Lei de Terras implementou uma política de regularização fundiária que beneficiou grandes proprietários e grileiros, ao longo da metade do séc. XIX, fazendo com que o Estado no Brasil se formasse baseado na propriedade privada.

No final do séc. XIX, a exploração da borracha chega ao seu auge, pois houve demanda do mercado internacional de produtos gomíferos, gerada pelo desenvolvimento tecnológico da revolução industrial, e houve a migração de trabalhadores nordestinos para a Amazônia em busca de oportunidades.

A proclamação da República em 1889, seguida da primeira Constituição Republicana em 1891, pôs fim ao regime da Lei de Terras e iniciou o período republicano, todavia, sem alterar a concepção de que a propriedade era um direito absoluto, encampada pelo Código Civil (CC) de 1916, de influência francesa.

Nesse passo, novas competências foram atribuídas aos Estados-membros e novos procedimentos de regularização fundiária foram adotados: as terras devolutas situadas em seus territórios foram entregues aos Estados, salvo as de fronteira (art. 64, Constituição de 1891), que permaneceram com a União (TRECCANI, 2009).

Ao mesmo tempo, os territórios etnicamente configurados, como áreas ocupadas por indígenas, ribeirinhos ou por comunidades quilombolas, foram considerados como terras devolutas, desocupadas e, consequentemente, disponíveis para expansão (PRIETO, 2016). De modo geral, para Loureiro (2009) a Amazônia era considerada pelo Estado e pela maior parte do restante do país, desde o passado colonial até a 
integração ao território nacional no séc. XIX, um espaço para a geração de riquezas e passível de exploração por outras regiões. Esta condição foi intensificada no decurso do séc. XX, com planos de desenvolvimento regional, que geraram um legado de exclusão social e que penalizaram indígenas, africanos e imigrantes, em especial nordestinos.

\section{O direito de propriedade no século XX e a Amazônia}

No séc. $X X$, com a influência do movimento de inserção de normas de cunho social nas Constituições, iniciado em 1917 no México e em 1919 na Alemanha, o Brasil promulga a Constituição de 1934, que implicitamente reconhece a função social da propriedade privada, ao dispor no art. 113, item 17, que a propriedade não poderá ser exercida contra o interesse social ou coletivo - o que representava um limite à noção de que a propriedade privada é um direito absoluto.

Em relação à Amazônia, até o final do séc. XIX, o povoamento da região havia se restringido ao vale do Amazonas e aos baixos vales de seus afluentes, sendo a partir da metade do séc. XX que a ocupação se intensificou, em face de ciclos da valorização de produtos extrativos no mercado internacional (BECKER, 2004). Até meados da década de 1960, as terras amazônicas pertenciam, basicamente, à União e aos Estados-membros (LOUREIRO; PINTO, 2005).

A ocupação da Amazônia se fez em surtos, conforme certos produtos eram valorizados no mercado internacional, lastreada em iniciativas externas com enfoque econômico, que termina exportando riquezas e bens naturais, ao mesmo tempo em que faz com que a riqueza gerada se concentre em elites regionais. Este cenário, que iniciou com a exploração de drogas do sertão, borracha e extrativismo vegetal, perdura até hoje, com a indústria madeireira, pecuária, de grãos e de minérios (LOUREIRO, 2009).

É possível associar a trajetória da Amazônia com ciclos econômicos, como o da borracha, até o governo militar no séc. XX, em que são implantados planos nacionais de desenvolvimento (BECKER, 2004).

Assim, a década de 1960 foi marcada pelo início da ditadura militar, instaurada em abril de 1964, sob o comando de governos que se estenderam até março de 1985 e que instauraram uma nova fase de ocupação do território amazônico. A título de ilustração, o Decreto Federal n ${ }^{0}$ 1.164, de 1971 instituiu um processo que ficou conhecido como federalização das terras amazônicas, em que áreas desta região eram transferidas para a União, desde que estivessem dentro da faixa de $100 \mathrm{~km}$ de cada de estradas federais existentes, em construção ou projetadas (LOUREIRO; PINTO, 2005). 
Em 1967 é estabelecido o Primeiro Plano Quinquenal de desenvolvimento que define os rumos da estratégia do governo baseado na segurança e na colonização. De modo semelhante, o I Plano Nacional de Desenvolvimento, estabelecido em 1972 buscava preencher o "vazio demográfico" da região, por meio da colonização oficial. Neste interregno é criado o Plano de Integração Nacional, com o lema integrar para não entregar.

Estes projetos ocasionaram vários impactos no território no que se refere à economia, ao meio ambiente e à sociedade local, dentre os quais cabe destacar a consolidação do processo de concentração fundiária nas mãos de poucas pessoas, grilagem, pistolagem, conflitos em torno da terra e o desmatamento (CASTRO, 2012).

No mesmo sentido, até este momento, a maior parte da terra era pública e a União e os Estados-membros passaram a aliená-la para grupos econômicos, empresários e segmentos sociais privilegiados por preços vantajosos. Enquanto isso, os moradores que viviam como meros detentores eram desfavorecidos, sem proteção legal da propriedade ou posse, e sem direito à aquisição da terra por meio de usucapião, pois este instrumento somente é aplicável aos imóveis privados (LOUREIRO, 2009).

A história, marcada por movimentos migratórios e de planos desenvolvimentistas, afetou o presente, pois o legado de normas que trataram do direito de propriedade e regularização fundiária, foi, para parcela da população, o de negação de direitos e de obrigar a viver na irregularidade, chegando a tomar tamanha proporção que resultou na implementação de programas de regularização fundiária no atual contexto.

A herança dos séculos anteriores de ocupação da Amazônia, que perpassa o Brasil Colonial, Brasil Império até o Brasil República, foi a sobreposição de títulos de sesmarias, registros de paróquias, de aforamentos, de ocupação, de posse, de cessão de uso, de propriedade, de terras confiscadas, vendidas, griladas e regularizadas por atos legais ou administrativos, documentos concedidos pelos governos imperiais, depois federais e estaduais, sem cancelar os títulos anteriores (LOUREIRO, 2009). Ao mesmo tempo, a mudança representada por um governo militar não alterou a trajetória de exploração de recursos da Amazônia.

\section{A Constituição de 1988 e as novas normas sobre regularização fundiária}

O período de redemocratização, após o final do governo militar, culminou com o advento da Constituição Federal de 1988 e com novas regras, concernentes à repartição de competências federativas e de normas sobre políticas urbanas. Se houve um processo de federalização de terras amazônicas iniciado em 1971, a década de 1990 começa a colher frutos da luta empreendida por movimentos de reforma 
urbana que defendia justamente o contrário: que a gestão do solo urbano deve ser atribuída aos municípios.

Segundo Klintowitz (2015), a partir do final da década de 1970 e do começo da década de 1980, setores progressistas se articulam, de maneira que movimentos sociais urbanos surgem em prol de valorização do trabalho, da saúde pública, gratuita e universal; da moradia popular, da construção de uma política urbana e habitacional.

O movimento de luta em favor da reforma urbana reivindicou a institucionalização de instrumentos legais que permitissem a gestão do solo para promover a inclusão social, o que culminou na inserção de um capítulo que trata de política urbana na Constituição Federal de 1988, em seus artigos 182 e 183, e no advento do Estatuto da Cidade - aplicáveis em todo o território nacional e para todas as esferas federativas.

A Constituição Federal de 88 determinou aos entes federados a competência comum de executar programas habitacionais, o que induziu um processo de descentralização, não coordenado de políticas habitacionais (KLINTOWITZ, 2015).

Ao lado desses acontecimentos, a Carta de 88 consagra a função social da propriedade em seu art. $5^{\circ}$, inciso XXIII ao dispor que a propriedade atenderá a sua função social, e reconhece esta função como princípio da ordem econômica (art. 170, inciso III, CF). Portanto, no sistema jurídico, a função social é parte integrante do conteúdo da propriedade privada (e pública), de maneira que a propriedade não se circunscreve aos interesses individuais, devendo atender ao interesse público.

O Código Civil de 2002 encampou estas ideias, do mesmo modo que o Estatuto da Cidade. No entanto, a regularização fundiária segue sendo tratada como exceção pela legislação e, nem sempre, ligada à política urbana municipal, o que torna seus resultados limitados.

Em outras palavras, ao se considerar o objetivo de democratizar o solo urbano, as mudanças legais que ocorreram no último século com a propriedade no Brasil foram positivas, mas de efeitos práticos restritos, fazendo com que a irregularidade fundiária continuasse sendo a regra.

Em 2008, com a constatação de que o quadro de indefinição fundiária, em que há dúvidas ou problemas legais na titulação de imóveis, atingia cerca de $50 \%$ do território da Amazônia (BRITO; BARRETO, 2011), o Governo Federal editou a Medida Provisória (MP) no 458/2009, cujo principal objetivo era superar o obstáculo que a ausência de regularidade representa para o desenvolvimento local e, assim, definir efetuar um reordenamento fundiário do território. Esta MP foi convertida na Lei $\mathrm{n}^{\mathrm{o}}$ 11.952/2009, que instituiu o PTL de regularização fundiária na Amazônia 
Legal. As normas do PTL devem ser aplicadas em conjunto a Lei no 13.465/2017, que disciplina a Reurb.

\section{A Análise de Políticas Públicas Fundiárias na Amazônia}

O estudo histórico-institucional traz substância e critérios para estudar as políticas públicas de regularização fundiária na Amazônia, que devem trazer previsibilidade à conduta humana, ao definir direitos de propriedade, além de ensejar o estudo do PTL, para verificar se houve mudança na trajetória desta região.

Sob outro ângulo, o institucionalismo histórico permite considerar a singularidade do momento, em que decisões são tomadas, para identificar conflitos entre atores e contexto, conforme as regras do jogo, que vão afetar o comportamento dos grupos sociais e indivíduos, combinando as regras erigidas socialmente com seu cálculo estratégico (STEINMO, 2008).

A partir da percepção da presença de agendas concorrentes para a implementação da política fundiária na Amazônia, coexistem atores com interesses contraditórios:

1. pessoas interessadas na grilagem de terras públicas;

2. indivíduos que são detentores de vários imóveis e podem se aproveitar disso para exercer influência sobre terceiros e podem se opor à Reurb;

3. políticos e/ou lideranças locais que podem apoiar ou se opor, conforme se beneficiem da Reurb; e

4. ocupantes de terrenos que residem legitimamente na área.

É necessário articular a problemática acerca do desempenho institucional do PTL na Amazônia, com suas implicações políticas, identificação dos principais atores nas arenas decisórias e análise dos fatores de estabilidade e de mudança na política fundiária na Amazônia. A Figura 1 mostra a trajetória da região. 
Figura 1 - Trajetória do problema fundiário na Amazônia.

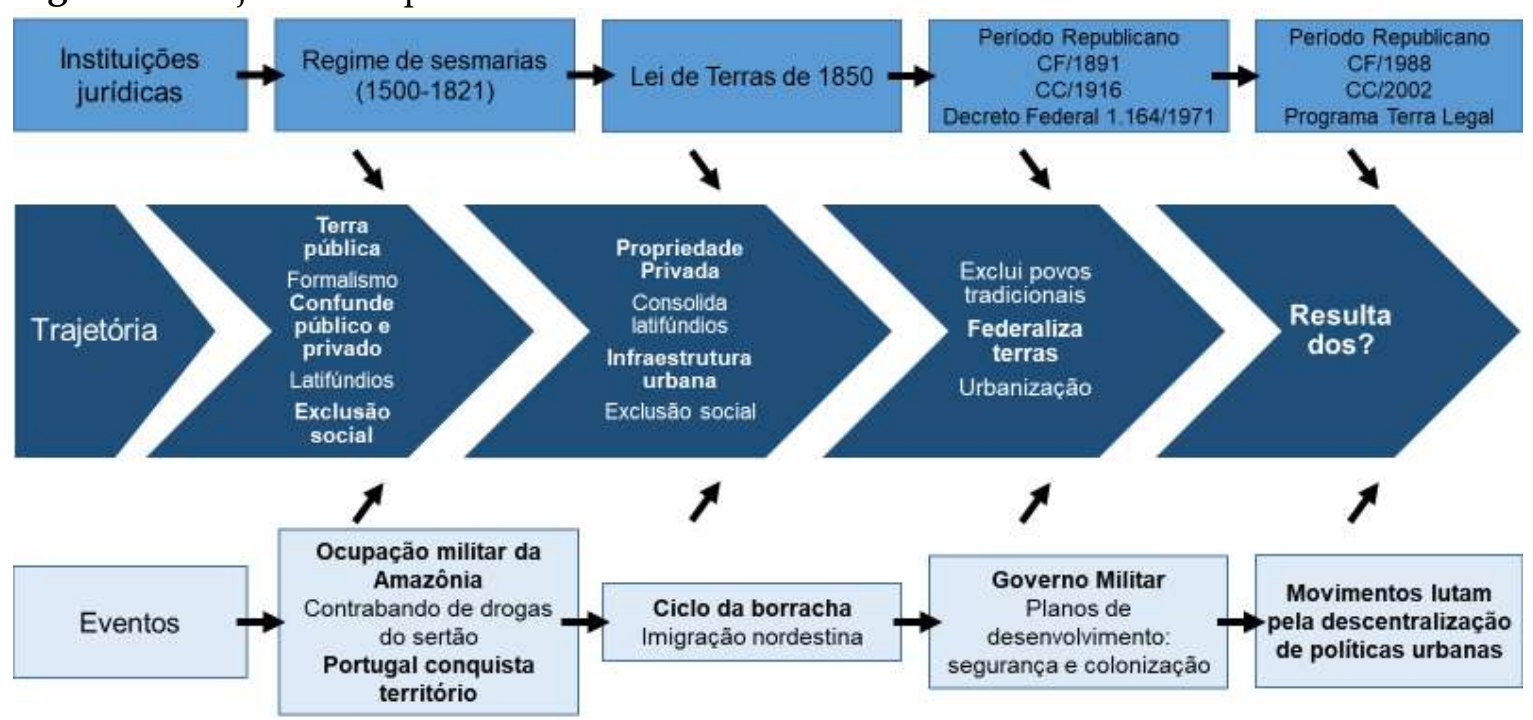

Fonte: Elaborado pelo autor, a partir da literatura (2018).

O entendimento deste caminho e das regras que foram permitindo a grilagem, latifúndios e a exclusão social ressaltam a relevância de se pensar em meios de se alterar a trajetória. Deve-se levar em consideração as consequências que os regimes de sesmarias e da Lei de Terras trouxeram à estrutura fundiária atual (OLIVEIRA; FISCHER, 2016), para saber se houve mudança institucional, o que pode ser feito se for constatado que há maior custo para alterar, em seguida, este novo rumo (SOTO, 2016). O PTL tem o potencial de efetivar mudanças, mas o jogo político pode trazer resultados inesperados.

Aparentemente, um programa de Reurb traz benefícios claros e não haveria motivo para se contrapor a ele (exceto, é claro ao se considerar a existências de múltiplas arenas e jogos ocultos). Mas a principal arena na qual os atores podem agir, em face da estrutura do PTL é a municipal, na medida em que após a adesão ao programa, não há espaço para discutir as regras federais, mas há margem para participar, alterar ou vetar as ações municipais, em especial por meio do Legislativo local. Dentre as mais variadas interações possíveis, a Figura 2 demonstra algumas possibilidades. 
Figura 2 - Casos de interações entre os atores na Arena municipal, após adesão ao Programa Terra Legal.

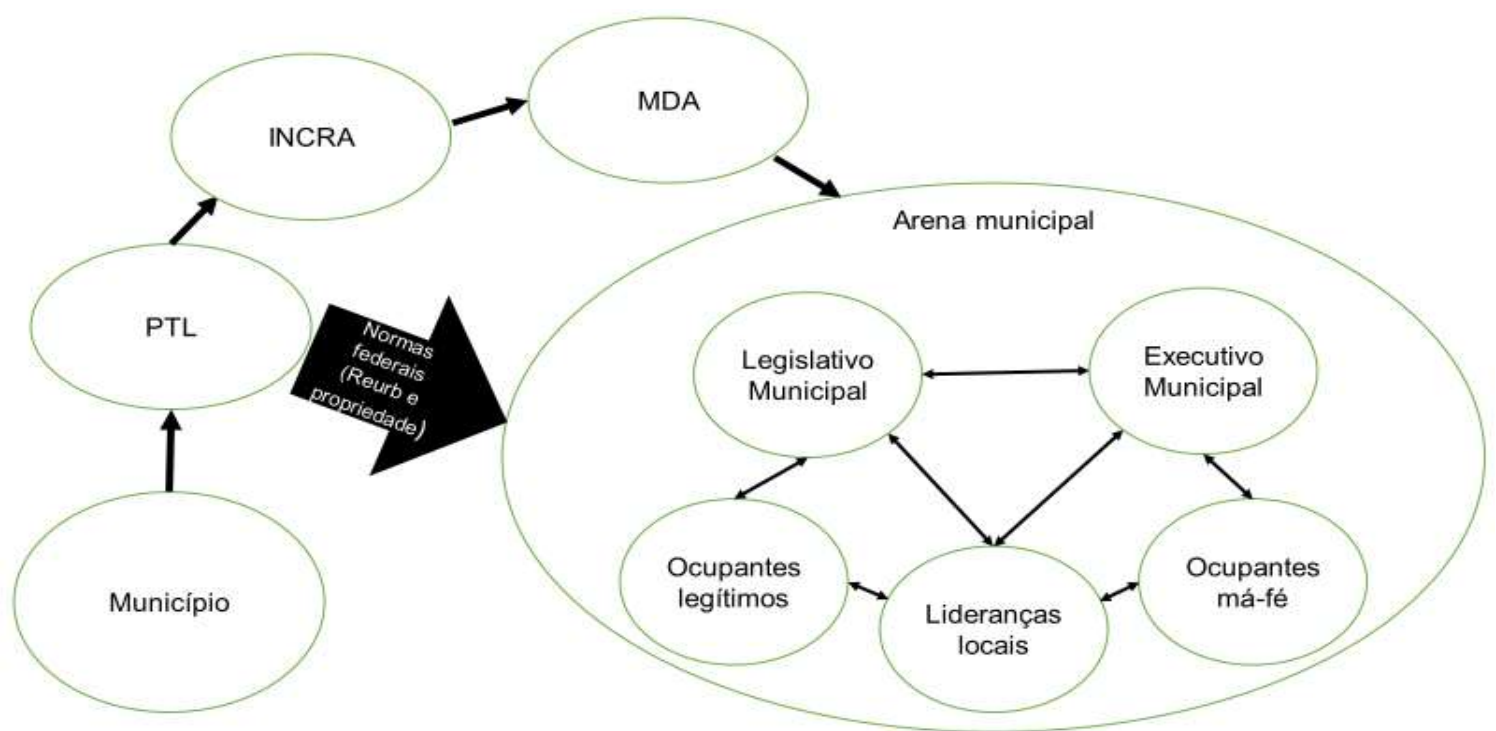

Fonte: Elaborado pelo autor, a partir da literatura (2018).

Alguns atores possuem interesses conflitantes, mas podem se unir para garantir a aprovação de regras que lhes favoreça. É interessante notar que a atuação dos agentes políticos (Prefeito e vereadores) abre espaço para a consideração de Tsebelis (1998) sobre jogos ocultos e poder de veto, pois estes players se deparam sempre com as eleições num espaço relativamente curto de tempo. Teoricamente, a arena municipal poderia ser subdividida em múltiplas arenas (como votação em comissões e no Plenário do Legislativo, discussão do projeto de Reurb na Prefeitura, reunião deliberativa com a comunidade civil, etc.), mas para fins da pesquisa, inicialmente, será considerada a existência de uma única arena. Assim, é possível proceder ao exame do PTL.

\section{A estrutura do Programa Terra Legal}

O PTL é, via de regra, aplicado na Amazônia Legal, em terras situadas em áreas da União - com a modificação promovida pela Lei $\mathrm{n}^{-}$13.465/2017, o PTL pode ser aplicada a imóveis fora da Amazônia Legal, desde que atenda ao disposto no art. 40A da Lei n⿳0 11.952/2009.

A Amazônia Legal foi criada com a finalidade de promover o desenvolvimento da região, pela Lei $n^{\circ} 1.806 / 1953$, e hoje está prevista no art. $2^{\circ}$, da lei complementar nº 124/2007, que abrange os seguintes Estados-membros: os Estados do Acre, Amapá, 
Amazonas, Mato Grosso, Rondônia, Roraima, Tocantins, Pará e do Maranhão na sua porção a oeste do Meridiano $44^{\circ}$.

A Amazônia Legal possui área territorial de aproximadamente $5.020 .000 \mathrm{~km}^{2}$, correspondendo a cerca de $60 \%$ do território nacional e abrangendo 776 municípios, cuja população é de 27.971.552 habitantes (BRASIL, 2017b).

Dentre os 502 milhões de hectares da Amazônia legal, 113 milhões (ou 22,5\% de sua área total) são terras federais, sendo 58 milhões com alguma destinação e o restante, 55 milhões, estava sem destinação até o início do PTL (RIBEIRO; SILVA; SANTOS, 2016).

A premissa é tratar da regularização fundiária rural e urbana, em que cada uma destas espécies conta com condicionantes e contornos próprios, mas trazendo, em ambas modalidades, a preferência para a titulação das comunidades locais.

$\mathrm{Na}$ regularização fundiária rural, os ocupantes devem atender às exigências legais, dentre as quais cabe destacar a ocupação e a exploração direta de atividade econômica exercida em imóvel rural, mansa e pacificamente, por si ou por seus antecessores, anterior a 22 de julho de 2008.

Na Reurb há o intuito de transferir o domínio pleno das terras federais ocupadas pela população aos municípios, com vistas a beneficiar a comunidade local.

Acontece que o PTL exige contrapartidas dos municípios para que possam ser beneficiados com a alienação das áreas. Nesses termos, o primeiro encargo é o de que as administrações locais promovam os atos necessários à regularização das áreas ocupadas (art. 21, §1ํㅡㄴ, Lei Federal no 11.952/2009).

O segundo requisito é a existência de lei municipal, que pode ser tanto o PDM, quanto outra lei específica, que abranja a área a ser regularizada (art. 22, § 1丷, Lei Federal $n^{0}$ 11.952/2009). Entretanto, quando se tratar de áreas com ocupações para fins urbanos já consolidadas a transferência da área poderá ser feita independentemente da existência da lei municipal referida (art. 22, §2º, Lei $\mathrm{n}^{\text {o }}$ 11.952/2009). De acordo com o art. 2o, I, “a” e “b”, do Decreto n⿳0 7.341/2010, que regulamenta o PTL, consideram-se áreas com ocupações para fins urbanos já consolidadas aquelas que apresentam sistema viário implantado com vias de circulação pavimentadas ou não, que configuram a área urbana por meio de quadras e lotes; uso predominantemente urbano, caracterizado pela existência de instalações e edificações residenciais, comerciais, voltadas à prestação de serviços, industriais, institucionais ou mistas, bem como demais equipamentos públicos urbanos e comunitários.

$\mathrm{O}$ art. $1^{\circ}$, parágrafo único da Lei $\mathrm{n}^{\mathrm{0}}$ 11.952/2009 proíbe beneficiar pessoa natural ou jurídica com a regularização de mais de uma área ocupada. No entanto, com a Lei 13.465/2017 ocorreram modificações em relação aos critérios que serviriam de guia 
para a atuação dos municípios. Anteriormente, as condicionantes presentes na Lei Federal 11.952/2009, estavam em seu art. 30. Em linhas gerais, existiam 4 situações:

1) alienação gratuita para ocupantes de baixa renda, em imóveis de até $1.000 \mathrm{~m}^{2}$, que tenham ingressado na área antes de fevereiro de 2009 e usem o imóvel como única moradia ou meio lícito de sobrevivência;

2) alienação onerosa, precedida de licitação, para imóveis entre $1.000 \mathrm{~m}^{2}$ e $5.000 \mathrm{~m}^{2}$;

3) alienação gratuita para órgãos e entidades da administração pública estadual $\mathrm{e}$;

4) nos demais casos, aplica-se a Lei de Licitações e Contratos (Lei 8.666/1993), em que é possível haver venda direta ou licitação.

Para ter direito à alienação gratuita do imóvel, o morador devia auferir renda familiar mensal inferior a 5 salários mínimos e ocupar área de até $1.000 \mathrm{~m}^{2}$, sem oposição, pelo prazo ininterrupto de, no mínimo, 1 ano, desde 2009, utilizando o imóvel como única moradia ou como meio lícito de subsistência, exceto locação ou assemelhado. Por fim, não podia ser proprietário ou possuidor de outro imóvel urbano.

Os casos de licitação são para imóveis acima de $1.000 \mathrm{~m}^{2}$, enquanto a alienação gratuita para órgãos e entidade estaduais estava ligada aos casos de haver prédios públicos nas glebas doadas. O último caso, aplicado de forma subsidiária, quando o imóvel não se enquadrasse nas hipóteses anteriores, é o da Lei de Licitações, que permite a venda direta, sem licitação, ou a alienação precedida de procedimento licitatório.

Atualmente, o art. 30 apenas afirma que o Município deverá efetuar a regularização fundiária das áreas doadas pela União mediante a aplicação dos instrumentos previstos na legislação federal específica da Reurb, que é a Lei $\mathrm{n}^{\mathbf{o}}$ 13.465/2017.

Esta nova lei teve a finalidade de desburocratizar os procedimentos da Reurb e trouxe novidades em relação aos institutos e mecanismos de regularização, além de alterar algumas regras do PTL, como a possibilidade de ser aplicado aos imóveis fora da Amazônia Legal. Dentre outras inovações, a Reurb agora também alcança imóveis em núcleos informais com características urbanas, mesmo que situados em zonas rurais; além de ter sido criado o direito real de laje; e a legitimação de posse ganhou contornos que a assemelham a um usucapião administrativo, sem necessidade de recorrer ao Judiciário.

Ao mesmo tempo, mantém outros institutos ou conceitos, como a distinção entre Reurb de interesse social, sendo aquela regularização fundiária aplicável aos núcleos urbanos informais ocupados predominantemente por população de baixa renda, declarados em ato do Executivo municipal; e Reurb de interesse específico, definida 
como aquela em que a população não está qualificada como de baixa renda. A diferença é importante porque, dentre outros fatores, há a flexibilização de parâmetros urbanísticos e uma série de isenções de custas e de emolumentos para a Reurb de interesse social.

Todavia, a maior novidade da Lei no 13.465/2017, quanto ao PTL, foi a determinação da utilização dos seus instrumentos de regularização, dentre os quais está a legitimação fundiária. Prevista nos artigos 23 e 24 desta lei, a legitimação fundiária constitui forma originária de aquisição do direito de propriedade, àquele que detiver em área pública ou possuir em área privada, como sua, unidade imobiliária com destinação urbana, integrante de núcleo urbano informal consolidado existente em 22 de dezembro de 2016.

O ocupante que adquirir a propriedade, mediante legitimação fundiária, recebe a unidade imobiliária livre e desembaraçada de quaisquer ônus, direitos reais, gravames ou inscrições, eventualmente existentes em sua matrícula de origem, e, por ser aquisição originária de propriedade, não incide pagamentos de tributos, como impostos de transferência de bens imóveis - Imposto sobre a Transmissão de Bens Imóveis e de direitos a eles relativos (ITBI) e Imposto sobre Transmissão "Causa Mortis" e Doação (ITCMD).

Ao se seguir a crítica feita por Prieto (2016), sobre a forma como as políticas de regularização fundiária foram sendo implementadas ao longo da história do Brasil, a possibilidade de adquirir uma propriedade pública sem ônus e sem nenhum outro requisito, exceto na modalidade de Reurb de interesse social, que não seja a ocupação do imóvel antes de 22 de dezembro de 2016, mais se assemelha a novas formas de grilagem e pode facilitar a acumulação de terras em favor de pessoas de alta renda, ao invés de democratizar o acesso ao solo urbano em favor de pessoas de baixa renda. O principal requisito na nova lei, aplicado somente na Reurb de interesse social, é que o ocupante não pode ser proprietário, concessionário ou foreiro de outro imóvel (art. 23, §1º̄, Lei n⿳o 13.465/2017). Na outra espécie de Reurb não há nenhum requisito além da ocupação do imóvel antes de 22 de dezembro de 2016.

Por fim, não se considera o tempo de ocupação e nem o tamanho do imóvel. Um imóvel com dimensões superiores a $1.000 \mathrm{~m}^{2}$ pode ter sido ocupado em novembro de 2016 e terá o mesmo tratamento que áreas ocupadas há décadas com lotes com menos de $100 \mathrm{~m}^{2}$.

Mas ficou claro que a tentativa de facilitar a Reurb modificou a política de regularização iniciada com o PTL, em 2009. A trajetória das políticas de regularização fundiária seguiu um padrão que permitiu a aglomeração de terras em benefício de poucos privilegiados em todo o Brasil e fez com que algo que era tratado como exceção e pontual demandasse a formulação de uma política duradoura de 
regularização.

Algumas pesquisas revelam que houve pouco avanço no PTL (RIBEIRO; SILVA; SANTOS, 2016; BRITO; BARRETO, 2011), resistência na utilização de instrumento oneroso de alienação pelos vereadores e pelos Prefeitos, dificuldade com as regras informais (OUTEIRO; GOÉS; NASCIMENTO, 2016), além do grande potencial em beneficiar grileiros (SAUER; LEITE, 2017).

Ribeiro; Silva; Santos (2016) concluem, após analisar o desenvolvimento do PTL em Rondônia entre os anos de 2009 a 2014, que apesar de ter beneficiados ocupantes de baixa renda, o programa gerou expectativas que não foram atendidas pelo ritmo lento de titulação (que segundo estimativas levaria 4 décadas para atender a todos os ocupantes), pelo número reduzido de beneficiados diante do número de imóveis existentes (menos de 5 mil ocupantes foram contemplados, num universo de mais de 43 mil) e por falhas no monitoramento e fiscalização das ações.

Com a edição da Lei 13.465/2017, fruto da conversão da MP no 759/2016, Sauer e Leite (2017) examinam os impactos que da lei nos processos de regularização fundiária, em face da ausência de critérios rígidos que dificultem a grilagem de terras, concluindo que se trata da MP da grilagem.

A regularização fundiária rural na Amazônia tem avançado, todavia, há um baixo rendimento operacional, a legislação continua permitindo a grilagem de terra e não reduz significativamente a insegurança jurídica das propriedades rurais, mesmo que tenham ocorrido melhoras no quesito transparência e no cancelamento de títulos ilegais (BRITO; BARRETO, 2011; RIBEIRO; SILVA; SANTOS, 2016) e, em alguns casos, pouco avança para democratizar o solo em favor de pequenos possuidores (CUNHA, 2009; OLIVEIRA, 2016). Em relação aos resultados do PTL na modalidade rural, até maio de 2016, foram emitidos 17.101 títulos de terra e, desses beneficiários, mais de $95 \%$ são agricultores familiares - isso em um universo de 3 milhões de hectares destinados ao PTL rural, que está dentro de outros 20 milhões de hectares não regularizados (ANDRADE et al., 2016).

$\mathrm{Na}$ Reurb não se encontram dados consolidados sobre sua efetividade, tendo em vista que é o município quem efetua as ações, mas estima-se que foram emitidos 11.000 títulos, correspondendo cerca de 5.7 milhões de hectares até 2017 (BRASIL, 2017a), deixando mais de 40 milhões da área na irregularidade - contando área urbana e rural.

De certa forma, a mudança na legislação não foi acompanhada de mudanças na mentalidade dos atores locais, que se compreendia donos do espaço e não apresentaram resistência quando o foco era a alienação gratuita, mas o conjunto de regras informais sobre uso e transferência do solo fez com que alguns conflitos sociais não fossem superados especialmente por parte dos atores políticos (OUTEIRO; GOÉS; NASCIMENTO, 2016).

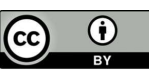


Há pesquisa que demonstra que nenhum município quis executar/instituir ações que delimitassem de maneira clara incentivos/sanções para a comunidade entender que haveria prejuízos em manter seu imóvel irregular. O discurso era sempre da parte positiva ou dos ganhos, sem tratar de eventuais danos por não aderir à Reurb (OUTEIRO, 2018).

É melhor para os políticos se beneficiarem com a alienação gratuita, sem ter o custo com a outra espécie de alienação. Dito de outro modo, é uma escolha racional dentro do jogo político (TSEBELIS, 1998) e utiliza os meios existentes para simplesmente vetar mudanças institucionais (CAPOCCIA, 2016).

Além disso, a despeito das restrições impostas aos imóveis irregulares, há um conjunto de regras informais que vem garantindo o funcionamento da ocupação e do mercado de compra e venda de áreas públicas das pessoas que residem nas áreas objeto de Reurb, independentemente do que diz o PTL, Constituição Federal, Código Civil, Lei de Parcelamento e Uso do Solo e etc., que não deve ser ignorado. As regras informais necessitam de maior tempo para serem alteradas.

Desta forma, não aplicar sanções duras, como remoção forçada, é uma saída para evitar antagonizar a comunidade local, mas algo deveria ser feito para que as regras informais, por mais que fosse lentamente, começassem a ser alteradas, como realizar campanhas informativas, que poderiam ser feitas por bairros, ou pequenos grupos para começar a disseminar a informação entre membros da sociedade

Ao se executar a Reurb segundo as novas regras, é possível projetar que todos os ocupantes atuais conseguirão obter a proteção da posse, independentemente da origem de sua relação com o terreno: grileiros, ocupantes legítimos, políticos.

É possível compreender o PTL como uma mudança nas regras formais, que não foi acompanhado pela estabilidade das regras informais e dos modelos de aprendizagem dos moradores e políticos locais, na mesma trajetória de exclusão social oriunda do regime de sesmarias, com pequenos ajustes incrementais.

Ao se afirmar que não houve mudança relevante na trajetória de exclusão socioespacial na região amazônica não se se quer dizer que algumas alterações institucionais não foram relevantes ao longo da história. A legislação atual não é a mesma do regime sesmarial nem se confunde com a Lei de Terras de 1850, além disso, a Constituição de 88 rompeu com o pensamento individual de propriedade privada absoluta e trouxe diretrizes para atuar no espaço urbano, que ganharam densidade no Estatuto da Cidade de 2001 e influenciaram o CC de 2002. O próprio reconhecimento de que cerca de metades dos imóveis na Amazônia Legal estavam em alguma situação de irregularidade fundiária, o que deu origem ao PTL é o reconhecimento de que as modificações institucionais não encontraram eco na realidade. Assim, a Figura 3 coloca a sucessão de molduras institucionais dentro da 
mesma trajetória, de uma forma didática, para que seja possível reconhecer que alterações foram efetivadas, todavia, não foram o suficiente para alterar o legado de exclusão social.

Figura 3 - Início da trajetória dependente de exclusão socioespacial no Brasil: do Regime de Sesmarias ao Programa Terra Legal

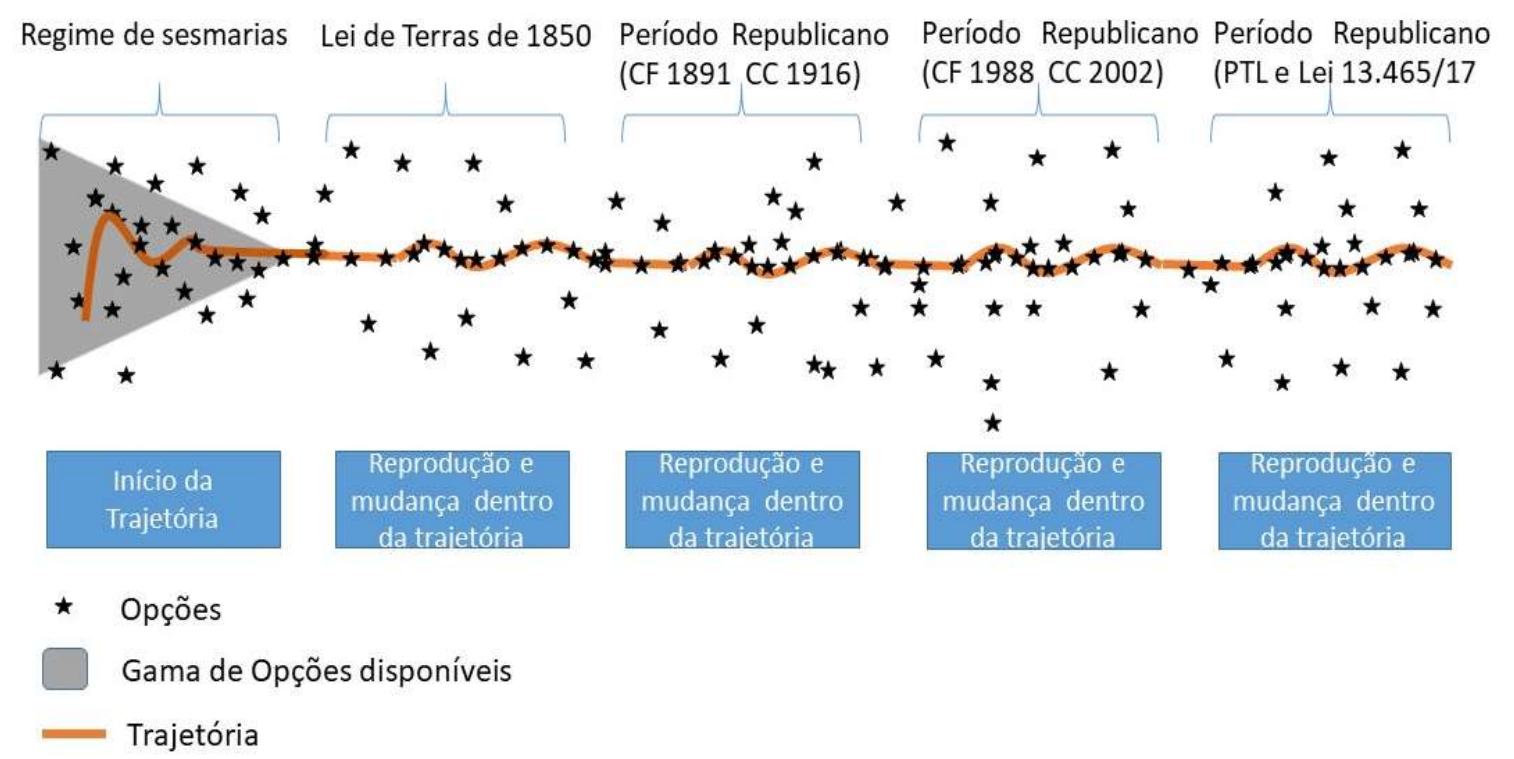

Fonte: Elaborado pelo autor, a partir da literatura e dos resultados da pesquisa (2018).

Se a mudança irá depender de como os atores, em especial as organizações, irão se aliar e complementar para transformar as regras formais de acordo com a existência de incentivos, seria possível atuar no âmbito local para que criar regras formais condizentes com o objetivo de democratizar o acesso ao solo.

Nenhum dos elementos necessários para falar destes temas estavam presentes, apesar de ter havido mais autonomia para os atores influenciarem a política urbana local.

Assim, algumas condições para mudar a herança de irregularidade podem ser sistematizadas em:

1) Utilizar instrumentos de Reurb que mantenham o domínio dos terrenos com os entes públicos por tempo limitado ou não, conforme o caso;

2) Modificar o PTL para utilizar critérios de inclusão social ao beneficiar com alienação gratuita para ocupantes de terras públicas e, enquanto não for modificado, que os municípios adotem critérios semelhantes; 
Como o desenho do PTL não consegue tratar o problema fundiário na Amazônia de forma adequada - seja na versão anterior, com a ausência de instrumentos de controle e fiscalização pela União e de gestão do solo pelos municípios (que priorizam a propriedade privada), nem na atual, em que não há critérios rígidos de inclusão social - por focar apenas na mudança das regras formais, com base nos argumentos construídos a partir dos resultados e da teoria, é importante manter alguma abertura para considerar a existência de regras informais locais.

\section{CONCLUSÃO}

O PTL se coaduna mais como um ajuste incremental dentro da mesma trajetória, com efeitos limitados, mas que permite grilagem de terras públicas e acumulação de terras. Isto porque os resultados do PTL se aproximam dos efeitos produzidos pelo regime de sesmaria e pela Lei de Terras (e subsequentes instituições formais), demonstrando a força do legado histórico, em que há apenas ajustes incrementais dentro do mesmo caminho.

Com efeito, com fundamento na trajetória anterior, e analisando o contexto histórico, é mais fácil prever que a Reurb será executada sem critérios rígidos que busquem uma reforma urbana igualitária.

São necessárias novas pesquisas para debater o assunto, afinal, o passado atua no presente e desenha o futuro, mas isso não quer dizer que não haja alternativas para mudar o amanhã e que o porvir seja inevitável.

\section{REFERÊNCIAS}

ABRAMOVICH, Vitor; COURTIS, Christian. El umbral de la ciudadanía: el significado de los derechos sociales em el Estado social constitucional. Buenos Aires: Del Puerto, 2006.

ANDRADE, Lucia Cristina et al. Programa Terra Legal? Quem são os beneficiários da regularização fundiária na Amazônia Legal? In: Seminário Governança de Terras e Desenvolvimento econômico, Campinas, 2016.

AZEVEDO, Flavio Ricardo. Entraves Jurídicos à Regularização Fundiária Individual no Estado do Pará: legislação fundiária paraense. 147 f. Dissertação (Mestrado). 
Programa de Pós-Graduação em Direito, Centro Universitário do Estado do Pará, Belém, 2016.

BECKER, Bertha Koiffmann. Amazônia: mudanças estruturais e tendências na passagem do milênio. In: MENDES, Armando Dias (Org.). Amazônia, terra e civilização: uma trajetória de 60 anos. Belém: Banco da Amazônia, 2004.

BRASIL. Ministério do Desenvolvimento Agrário (MDA). A evolução do Programa Terra Legal em oito anos de atuação. 2017 (2017a). Disponível em $<$ http://www.mda.gov.br/sitemda/evolução-do-programa-terra-legal-em-oito-anosde-atuação>. Acesso em: 26 nov. 2017.

BRASIL. IBGE. Pesquisa Nacional por Amostra de Domicílios (PNAD) 2015. Disponível em: <http://www.ibge.gov.br/home/estatistica/pesquisas/pesquisa_ resultados.php?id_pesquisa=40>. Acesso em: 10 jul. 2018.

BRASIL. IBGE. Brasil em síntese. 2017 (2017b). Disponível em: $<$ https://cidades.ibge.gov.br/ brasil>. Acesso em: 10 maio 2018.

BRITO, Brenda; BARRETO, Paulo. A regularização fundiária avançou na Amazônia?: os dois anos do Programa Terra Legal. Belém: IMAZON, 2011.

CAPOCCIA, Giovanni. When do institutions "bite? Historical institutionalism and the politics of institutional change. Comparative Political Studies, v. 49, n. 8, p. 10951127, 2016.

CAPOCCIA, Giovanni; KELEMEN, Daniel. The Study of Critical Junctures: Theory, Narrative, and Counterfactuals in Historical Institutionalism. World Politics, v. 59, n. 3, p. 341-369, 2007.

CASTRO, Edna. Expansão da fronteira, megaprojetos de infraestrutura e integração sul-americana. Caderno CRH, v. 25, p. 45-62, 2012.

CUNHA, Cândido Neto. "Pintou uma chance legal" o programa "Terra Legal" no interior dos projetos integrados de colonização e do polígono desapropriado de Altamira, no Pará. Agrária, São Paulo, n. 10 -11, p. 20-56. 2009. 
FAORO, Raymundo. Os Donos do Poder: formação do patronato político brasileiro. 3. ed. rev. São Paulo: Globo, 2001.

FERNANDES, Antonin Sérgio Amiíjo. Path dependency e os Estudos Históricos Comparados. BIB, São Paulo, n. 53, p. 79 -102, 2002.

FRIEL, Daniel. Understanding institutions: different paradigms, different conclusions. Revista de Administração, v. 52, p. 212-214, 2017.

HALL, Peter; TAYLOR, Rosemary. Political science and the three new institucionalism. Political Studies, v. 44, p. 936-957, 1996.

HOLMES, Stephen; SUNSTEIN, Cass. The cost of rights: why liberty depends on taxes. Nova York: W. W. Norton \& Company, 1999.

IMMERGUT, Ellen. Historical-Institutionalism in Political Science and the Problem of Change. In: WIMMER, Andreas; KÖSSLER, Reinhart (Ed.). Understanding Change. New York/Basingstoke: Palgrave/Macmillan, p. 237-259, 2006.

KLINTOWITZ, Danielle Cavalcanti. Entre a Reforma Urbana e a Reforma Imobiliária. 256 f. Tese (Doutorado). Escola de Administração de Empresas de São Paulo da Fundação Getúlio Vargas, 2015.

LEVI, Margaret. Uma lógica da mudança institucional. Dados NR, v. 34, n. 1, p. 7999, 1991.

LISBOA, José Herbert Luna; LIMA, Anna Caroline Lopes Correia. Regularização Fundiária Urbana: Direito Humano à Moradia Digna, um dos Instrumentos de Combate à Desigualdade Social. Revista de Direito Urbanístico, Cidade e Alteridade, v. 2, n. 1, p. $274-292,2016$.

LOUREIRO, Violeta Refkalefsky; PINTO, Jax Nildo Aragão. A questão fundiária na Amazônia. Estudos Avançados, Universidade de São Paulo, v. 2, n. 54, p. 77-98, 2005. 
LOUREIRO, Violeta Refkalefsky. A Amazônia no Século XXI: novas formas de desenvolvimento. São Paulo: Empório do Livro, 2009.

NORTH, Douglass. Institutions, Institutional Change and Economic Performance. Cambridge: Cambridge University Press, 1990.

OLIVEIRA, Gustavo de Lima Torres. Regularização fundiária e a "corrida mundial por terras" no Brasil. Campo-Território: Revista de Geografia Agrária, v. 23, n. 23, jul, 2016.

OLIVEIRA, Natalia Altieri; FISCHER, Luly Rodrigues. Efeitos da Lei de Terras nas Relações Socioespaciais na Amazônia. Revista Brasileira de História do Direito, v. 2, n. 2, p. 19-38, 2016.

OUTEIRO, Gabriel Moraes; GÓES, David Souza; NASCIMENTO, Durbens Martins. Neoinstitucionalismo, regularização fundiária urbana e o Programa Terra Legal.

Novos Cadernos NAEA, v. 19, n. 2, 2016.

OUTEIRO, Gabriel Moraes. Regularização Fundiária Urbana na Amazônia: um estudo comparativo do Programa Terra Legal nos Estados do Pará e Amapá. 257 f. Tese (Doutorado). Programa de Pós-Graduação em Desenvolvimento Sustentável do Trópico Úmido, Núcleo de Altos Estudos Amazônicos, Universidade Federal do Pará, Belém, 2018.

PRIETO, Gustavo Francisco Teixeira. Rentismo à brasileira, uma via de desenvolvimento capitalista. 742 f. Tese (Doutorado) - Programa de Pós-Graduação em Geografia Humana, Faculdade de Filosofia, Letras e Ciências Humanas, Universidade de São Paulo, São Paulo, 2016.

RIBEIRO, Alyson Fernando Alves; SILVA, Ricardo Gilson da Costa; SANTOS, Josefa de Lisboa. Política de regularização fundiária em Rondônia: limitações do programa terra legal e expectativas socioterritoriais. Confins, Paris, v. 29, p. 01, 2016.

SÁ, Rafael Amorim Martins. Regularização fundiária de interesse social: questões ambientais, sociais e jurídicas. 97 f. Dissertação (Mestrado). Programa de Pós- 
Graduação em Desenvolvimento e Planejamento Territorial, Pontifícia Universidade Católica de Goiás. Goiânia. 2017.

SAUER, Sérgio; LEITE, Acácio Zuniga. Medida Provisória 759: descaminhos da reforma agrária e legalização da grilagem de terras no Brasil. Retratos de Assentamentos, v. 20, n. 1, p. 14-40, 2017.

SKOCPOL, Theda; PIERSON, Paul. Historical Institutionalism in contemporary Political Science. In: KATZNELSON, Ira, MILNER, Helen. Political Science: State of the Discipline. New York: W.W. Norton, p. 693-721, 2002.

SOTO, Luis Gonzalo. Una revisión de los aportes del institucionalismo histórico a la ciencia política. Revista Colombiana de Ciencias Sociales, v. 7, n. 1, p. 224-241, 2016.

STEINMO, Sven. What is Historical Institutionalism. In: DELLA PORTA, Donatella; KEATING, Michael. Approaches in the Social Sciences. Cambridge: Cambridge University Press, p. 150-178, 2008.

TAVARES, Maria Goretti da Costa. A Amazônia brasileira: formação históricoterritorial e perspectivas para o século XXI. Espaço e Tempo, São Paulo, v. 29, n. especial, p. 107-121, 2011.

THELEN, Kathleen. Historical Institutionalism in Comparative Politics. Annual Review of Political Science, v. 2, p. 369-404, 1999.

TRECCANI, Girolamo Domenico. O Título de posse e a legitimação de posse como formas de aquisição da propriedade. Revista da Procuradoria Geral do Estado do Pará. Belém: Procuradoria Geral do Estado do Pará, n. 20, p. 121-158, 2009.

TSEBELIS, George. Jogos ocultos: escolha racional no campo da política comparada. São Paulo: Universidade de São Paulo, 1998. 